\title{
ANALISIS PENGARUH SUMBER DAYA MANUSIA DAN STRUKTUR ORGANISASI TERHADAP IMPLEMENTASI KEBIJAKAN PENGEMBANGAN PARIWISATA PADA DINAS KEBUDAYAAN DAN PARIWISATA KABUPATEN BANJAR
}

\author{
Faizal Riza Kasransyah \\ Sekolah Tinggi Ilmu Ekonomi Pancasetia Banjarmasin \\ Jl. Ahmad Yani Km. 5.5 Banjarmasin \\ myogaaditya@gmail.com
}

\begin{abstract}
The purpose of this study was to determine and analyze the effect of human resources and organizational structure partially and simultaneously on the implementation of tourism development policies in the Department of Culture and Tourism of the Regency of Banjar. This research uses a quantitative method, with a survey approach, with the purpose of explanation (explanatory research). The analysis tool used is a simple regression test. Sampling using a questionnaire method the number of samples as many as 60 employees of the Department of Culture and Tourism Banjar District. The results showed that the human resource variable partially influenced the implementation of tourism development policies. The organizational structure variable partially has no effect on the implementation of tourism development policies. Meanwhile, simultaneously there is the influence of human resource variables and organizational structure simultaneously on the implementation of tourism development policies at the Department of Culture and Tourism of the Regency of Banjar. The contribution of the independent variable to the dependent variable is $49.8 \%$.
\end{abstract}

Keywords: human resources, organizational structure, policy implementation

\begin{abstract}
Abstrak: Tujuan penelitian ini adalah untuk mengetahui dan menganalisis pengaruh sumber daya manusia dan struktur organisasi secara parsial dan simultan terhadap implementasi kebijakan pengembangan pariwisata pada Dinas Kebudayaan dan Pariwisata Kabupaten Banjar. Penelitian ini menggunakan metode kuantitatif, dengan pendekatan survey, dengan maksud penjelasan (explanatory research). Adapun alat analisis yang digunakan adalah uji regresi sederhana. Pengambilan sampel menggunakan metode Kuesioner jumlah sampel sebanyak 60 orang pegawai Dinas Kebudayaan dan Pariwisata Kabupaten Banjar. Hasil penelitian menunjukkan bahwa variabel sumber daya manusia secara parsial berpengaruh terhadap implementasi kebijakan pengembangan pariwisata. Variabel struktur organisasi secara parsial tidak berpengaruh terhadap implementasi kebijakan pengembangan pariwisata. Sedangkan, secara simultan terdapat pengaruh variabel sumber daya manusia dan struktur organisasi secara simultan terhadap implementasi kebijakan pengembangan pariwisata pada Dinas Kebudayaan dan Pariwisata Kabupaten Banjar. Kontribusi variabel bebas terhadap variabel terikat sebesar $49,8 \%$
\end{abstract}

Kata kunci: sumber daya manusia, struktur organisasi, implementasi kebijakan 


\section{Latar Belakang}

Pariwisata merupakan salah satu pilar utama yang digalakkan oleh pemerintah dalam pembangunan berkelanjutan. Pariwisata menjadi penyumbang produk domestik bruto, devisa bagi suatu negara. Jumlah kunjungan wisata dari tahun ke tahun di Indonesia mengalami peningkatan. Berdasarkan surat keterangan pers dari Biro Hukum dan Komunikasi Publik Kementrian Pariwisata, jumlah kunjungan wisatawan mancanegara (wisman) ke Indonesia pada September 2016 mencapai 1.006.653 atau mengalami peningkatan sebesar 9,40\% dibandingkan September 2015 yang berjumlah 920.128 wisman. Selama tiga bulan berturut-turut, yakni dari Juli, Agustus, dan September 2016 jumlah kunjungan wisman menembus angka di atas 1 juta wisman (Data Kementerian Pariwisata tahun, 2016)

Pariwisata di Indonesia tersebar diberbagai daerah dari Sabang sampai Merauke, sehingga untuk memudahkan pengembangannya maka masing-masing daerah mempunyai wewenang sendiri dalam mengembangkan paiwisata yang ada. Hal ini juga berdasarkan pada pelaksanaan UU No 23 Tahun 2014 mengenai pemberlakuan Otonomi Daerah, dengan ini Pemerintah Daerah bertanggung jawab untuk mengembangkan dan mengelola segala potensi yang ada didaerahnya masing-masing. Hal tersebut juga berlaku untuk pariwisata, karena pariwisata merupakan salah satu potensi yang dimiliki oleh suatu daerah.

Berkembangnya pariwisata di suatu daerah akan mendatangkan banyak manfaat bagi masyarakat, yakni secara ekonomis, sosial dan budaya; namun jika pengembangannya tidak dipersiapkan dan tidak dikelola dengan baik, justru akan menimbulkan banyak permasalahan yang menyulitkan atau bahkan merugikan masyarakat. Untuk menjamin supaya pariwisata dapat berkembang secara baik dan berkelanjutan serta mendatangkan manfaat bagi manusia dan meminimalisasi dampak negatif yang mungkin timbul, maka pengembangan pariwisata perlu didahului dengan kajian yang mendalam, yakni dengan melakukan penelitian terhadap semua sumber daya pendukungnya (Wardiyanta, 2010).

Kabupaten Banjar merupakan salah satu daerah yang kaya akan potensi pariwisata dan menjadi destinasi unggulan di Kalimantan Selatan karena kondisi geografis dan topografisnya. Adapun potensi daya tarik wisata yang dimiliki Kabupaten Banjar yaitu kesenian tradisional, tari, wisata kuliner, wisata alam, wisata pengunungan, wisata sejarah, wisata geologi, wisata pendidikan, wisata tradisi, hingga wisata buatan.

Potensi pariwisata di Kabupaten Banjar sangat prospektif untuk terus dikembangkan dimasa depan, khususnya wisata alam yang memiliki daya tarik tersendiri bagi wisatawan nusantara maupun mancanegara. Berdasarkan data Dinas Pariwisata dan Kebudayaan Kabupaten Banjar pengunjung pada tahun 2019 mencapai 600.595 wisatawan atau mengalami peningkatan sebesar $24,3 \%$ dibandingkan tahun 2018 yang berjumlah 483.428 wisatawan.

Kebijakan pengembangan pariwisata di Kabupaten Banjar tertuang pada Logframe Rencana Pembangunan Jangka Menengah Dinas Pariwisata dan Kebudayaan. Logframe RPJM Dinas Pariwisata dan Kebudayaan berisi tentang program fisik maupun non fisik yang ditujukan untuk pengembangan pariwisata di Kabupaten Banjar yang mengacu pada Penyusunan Rencana Terpadu dan Program 
Investasi Infrastruktur Jangka Menengah Kabupaten Banjar Tahun 2015-2019 yang ditujukan untuk mengatasi berbagai permasalahan terkait pengembangan pariwisata.

Dalam mengembangkan pariwisata di Kabupaten Banjar, Pemkab Banjar dihadapkan pada dua masalah utama. Adapun masalah tersebut meliputi: (1) sarana dan prasarana yang masih minim diberbagai kawasan obyek wisata. Sarana penunjang seperti kamar mandi umum, tempat sampah, akses jalan, serta tempat parkir belum maksimal, (2) Wilayah pariwisata belum dikembangkan secara optimal, selama ini pemerintah hanya terpaku pada pengelolaan pariwisata di kawasan tertentu saja. Kawasan lain seperti kawasan peruntukan wisata alam, kawasan peruntukan pariwisata belanja, serta kawasan peruntukan pariwisata budaya dan cagar budayabelum dikembangkan secara optimal.

Teori dari Edward III untuk menganalisis keberhasilan implementasi kebijakan pariwisata. Edward mengajukan empat faktor yang berperan penting dalam pencapaian keberhasilan implementasi. Faktor-faktor yang mempengaruhi keberhasilan atau kegagalan implementasi kebijakan yaitu faktor komunikasi (communication), sumber daya (resources), disposisi (disposition), dan struktur organisasi (bureucratic structure) (Edward dalam Widodo 2007:97).

Menurut Van Metter dan Van Horn yang dikutip oleh Agustino, "sumber daya merupakan keberhasilan proses implementasi kebijakan yang dipengaruhi dengan pemanfaatan sumber daya manusia, biaya, dan waktu" (Meter dan Horn dalam Agustino, 2007:142). Sumber-sumber kebijakan itu sangat dibutuhkan untuk menentukan berhasil atau tidaknya suatu kebijakan yang dibuat oleh pemerintah. Sumber daya manusia merupakan motor penggerak dan pelaksana kebijakan, anggaran dibutuhkan untuk kelancaran pembiayaan kebijakan agar tidak menjadi penghambat proses kebijakan. Sedangkan waktu adalah bagian terpenting dalam pelaksanaan kebijakan, karena waktu merupakan pendukung keberhasilan kebijakan. Sumber daya waktu merupakan salah satu penentu pemerintah dalam merencanakan dan melaksanakan kebijakan.

Menurut Van Meter dan Van Horn yang dikutip oleh Subarsono, bahwa "karakteristik agen pelaksana adalah mencakup struktur birokrasi, norma-norma, dan pola-pola hubungan yang terjadi dalam birokrasi”. Sikap dan perlaku para pelaksana dalam menjalankan tugas dan tanggungjawab sebagai pelaksana kebijakan harus dilandasi dengan sikap yang kuat, tegas dan disiplin. Hal tersebut dilakukan karena akab berpengaruh terhadap berhasil atau tidaknya implementasi kebijakan, setiap badan/instansi pelaksana kebijakan (Meter dan Horn dalam Subarsono, 2010:101).

Penelitian ini juga mengacu pada konsep kepariwisataan Indonesia terdapat empat misi menurut Mulyadi (2012:26). Empat misi tersebut berangkat dari sebuah konsep bahwa kepariwisataan memiliki tuntutan untuk mengendalikan diri yang mengutamaka manusia sebagai subjek sentral. Kepariwisataan berorientasi dari rakyat, oleh rakyat dan untuk rakyat sehingga kekuatan inti pariwisata Indonesia berada ditangan rakyat atau disebut kepariwisataan berbasis masyarakat (Community Based Tourism Development). Dibawah ini adalah empat misi Kepariwisataan Indonesia meliputi: (1) pemberdayaan dan peningkatan peran serta 
masyarakat dalam mengembangkan kepariwisataan, (2) pemanfaatan kebudayaan untuk kepariwisataan guna kepentingan agama, pendidikanm ilmu pengetahuan, ekonomi, persatuan dan kesatuan serta persahabatan antar bangsa, (3) pengembangan produk kepariwisataan yang berwawasan lingkungan bertumpu pada budaya daerah, pesona alam, pelayanan prima dan berdaya saing global, (4) pengembangan sumber daya manusia Kepariwisataan yang sehat, berakhlak mulia dan profesional.

Tujuan dari penelitian ini adalah 1) Untuk menganalisis pengaruh variabel sumber daya manusia secara parsial terhadap implementasi kebijakan pengembangan pariwisata pada Dinas Kebudayaan Dan Pariwisata Kabupaten Banjar. 2) Untuk menganalisis pengaruh variabel struktur organisasi secara parsial terhadap implementasi kebijakan pengembangan pariwisata pada Dinas Kebudayaan dan Pariwisata Kabupaten Banjar. 3) Untuk menganalisis variabel sumber daya manusia dan struktur organisasi yang memiliki pengaruh secara simultan terhadap implementasi kebijakan pengembangan pariwisata pada Dinas Kebudayaan dan Pariwisata Kabupaten Banjar.

\section{Studi Literatur}

\section{Manajemen Sumber Daya Manusia}

Manajemen bukan saja mengelola sumber daya manusia, tetapi juga material, modal dan faktor produksi lainnya. Tetapi bagaimanapun juga, sumber daya manusia merupakan salah satu faktor produksi yang paling penting yang harus dimiliki oleh setiap organisasi, maka konsekuensi dari semua itu adalah perlunya pengelolaan sumber daya manusia secara lebih baik agar diperoleh sumbangan yang berarti bagi kemajuan organisasi atau perusahaan.

Berikut adalah beberapa pengertian manajemen sumber daya manusia menurut para ahli, menurut Hasibuan (2011:10), Manajemen Sumber Daya Manusia adalah ilmu dan seni mengatur hubungan dan peranan tenaga kerja agar efektif dan efisien membantu terwujudnya tujuan perusahaan, karyawan dan masyarakat.

Handoko (2012:4), mengemukakan bahwa: Manajemen Sumber Daya Manusia adalah proses penarikan, seleksi, pengembangan, pemeliharaan, dan penggunaan sumber daya manusia untuk mencapai tujuan individu maupun organisasi .

Mangkunegara (2012:2) mengatakan : Manajemen Sumber Daya Manusia merupakan suatu perencanaan, pengorganisasian, pengkoordinasian, pelaksanaan, dan pengawasan terhadap pengadaan, pengembangan, pemberian balas jasa, pengintegrasian, pemeliharaan, dan pemisahan tenaga kerja dalam rangka mencapai tujuan organisasi.

\section{Sumber Daya Manusia}

Sumber daya manusia adalah orangorang yang ada dalam organisasi yang memberikan sumbangan pemikiran dan melakukan berbagai jenis pekerjaan dalam mencapai tujuan organisasi. Sumbangan yang dimaksud adalah pemikiran dan pekerjaan yang mereka lakukan di berbagai kegiatan dalam perusahaan. Dalam pengertian sumber daya manusia, yang diliput bukanlah terbatas kepada tenaga ahli, tenaga pendidikan ataupun tenaga yang berpengalaman saja tetapi semua tenaga kerja yang digunakan perusahaan untuk mewujudkan tujuan-tujuannya. (Sukirno, 2006) 
Kata "Sumber Daya" menurut Poerwadarminta, menjelaskan bahwa dari sudut pandang etimologis kata "sumber" diberi arti "asal" sedangkan kata "daya" berarti "kekuatan" atau "kemampuan". Dengan demikian sumber daya artinya "kemampuan", atau "asal kekuatan". Pendapat lain mengatakan bahwa Sumber Daya diartikan sebagai alat untuk mencapai tujuan atau kemampuan memperoleh keuntungan dari kesempatankesempatan tertentu, atau meloloskandiri dari kesukaran sehingga perkataan sumber daya tidak menunjukkan suatu benda, tetapi dapat berperan dalam suatu proses atau operasi yakni suatu fungsi operasional untuk mencapai tujuan tertentu seperti memenuhi kepuasan. Dengan kata lain sumber daya manusia merupakan suatu abstraksi yang mencerminkan aspirasi manusia dan berhubungan dengan suatu fungsi atau operasi.

Untuk memahami pengertian Sumber Daya Manusia (SDM) perlu dibedakan antara pengertiannya secara makro dan mikro. Pengertian SDM secara makro adalah semua manusia sebagai penduduk atau warga negara suatu negara atau dalam batas wilayah tertentu yang sudah memasuki usia angkatan kerja, baik yang sudah memasuki usia angkatan kerja, baik yang sudah maupun memperoleh pekerjaan. Di samping itu SDM secara makro berarti juga penduduk yang berada dalam usia produktif, meskipun karena berbagai sebab dan masalah masih terdapat yang belum produktif karena belum memasuki lapangan kerja yang terdapat di masyarakatnya. (Martoyo, 2002)

\section{Struktur Organisasi}

Dalam pengertian sederhana
organisasi sering diartikan sebagai
kelompok orang yang bekerjasama dan ingin mencapai tujuan bersama. Organisasi didirikan karena beberapa tujuan tertentu yang hanya dapat dicapai melalui tindakan yang harus dilakukan bersama-sama, apakah tujuan itu berupa laba, pemberian pendidikan, sosial dan lain-lain.

Struktur organisasi dapat diartikan sebagai kerangka kerja formal organisasi yang dengan kerangka kerja itu tugas-tugas pekerjaan dibagi-bagi, dikelompokkan, dan dikoordinasikan (Robbins dan Coulter, 2007:284). Struktur organisasi didefinisikan sebagai mekanismemekanisme formal dengan mana organisasi dikelolah (Handoko, 2003:169). Struktur organisasi adalah pola formal mengelompokkan orang dan pekerjaan (Gibson dkk, 2002:9).

Struktur organisasi yaitu menggambarkan tipe organisasi, pendepartemenan organisasi, kedudukan dan jenis wewenang pejabat, bidang dan hubungan Universitas Sumatera Utara pekerjaan, garis perintah dan tanggungjawab, rentang kendali dan sistem pimpinan organisasi (Hasibuan, 2004:128). Menurut Sunarto (2003;210) struktur organisasi menetapkan bagaimana tugas pekerjaan dibagi, dikelompokkan dan dikoordinasi secara formal. Robbin (2003:214) menyatakan bahwa struktur organisasi adalah rantai perintah yang digambarkan secara grafis dengan menggunakan bagan organisasi

\section{Metode Penelitian}

Jenis penelitian kuantitatif menggunakan metode survey dengan mengajukan alat pertanyaan atau instrumen penelitian untuk mengumpulkan data dalam bentuk kuesioner. Fokus penelitian kuantitatif diidentifikasikan sebagai proses kerja yang berlangsung secara ringkas, terbatas, dan memilah-milah permasalahan 
sehingga menjadi bagian yang dapat diukur atau dinyatakan dalam angka-angka. Analisis data menggunakan regresi linier berganda.

\section{Hasil Penelitian dan Pembahasan}

Pengumpulan data dilakukan dengan menyebar 60 kuesioner. Berikut karakteristik responden yang ditemui dilapangan :

Tabel 1

Jenis Kelamin Responden

\begin{tabular}{|c|c|c|}
\hline $\begin{array}{c}\text { Jenis } \\
\text { kelamin }\end{array}$ & F & $\%$ \\
\hline Laki-laki & $\mathbf{2 9}$ & $\mathbf{4 8 , 3 \%}$ \\
\hline Perempuan & $\mathbf{3 1}$ & $\mathbf{5 1 , 7 \%}$ \\
\hline Jumlah & $\mathbf{6 0}$ & $\mathbf{1 0 0 \%}$ \\
\hline
\end{tabular}

Dari 60 responden dalam penelitian ini, terdapat responden laki-laki sebanyak 33 orang $(48,3 \%)$ dan responden perempuan sebanyak 67 orang $(51,7 \%)$.

Tabel 2

Pendidikan Responden

\begin{tabular}{|l|l|l|}
\hline Pendidikan & F & \% \\
\hline SMA & 7 & $11,7 \%$ \\
\hline Diploma & 11 & $18,3 \%$ \\
\hline S1 & 39 & $65,0 \%$ \\
\hline S2 & $\mathbf{3}$ & $\mathbf{5 , 0 \%}$ \\
\hline Jumlah & $\mathbf{6 0}$ & $\mathbf{1 0 0 \%}$ \\
\hline
\end{tabular}

Bahwa dari 60 responden dalam penelitian ini, terdapat responden pendidikan S1 sebanyak 39 orang (65\%), Diploma sebanyak 11 orang $(18,3 \%)$, SMA sebanyak 7 orang $(11,7 \%)$, dan S2 sebanyak 3 orang $(5 \%)$.

Tabel 3

Usia Responden

\begin{tabular}{|l|l|l|}
\hline Usia & $\begin{array}{l}\text { Jumlah } \\
\text { responden }\end{array}$ & Persentase \\
\hline 21-30 tahun & 12 & $\mathbf{2 0 . 0}$ \\
\hline 31-40 tahun & 21 & 35.0 \\
\hline
\end{tabular}

\begin{tabular}{|l|l|l|}
\hline 41-50 tahun & 15 & 25.0 \\
\hline$>$ 50 tahun & 12 & 20.0 \\
\hline Jumlah & 60 & $100 \%$ \\
\hline
\end{tabular}

Dari 60 responden dalam penelitian ini terdapat responden kelompok usia 31-40 tahun sebanyak (35\%), usia 41-50 tahun sebanyak 15 orang (25\%), usia 21-30 tahun sebanyak 12 orang $(20 \%)$, dan $>50$ tahun sebanyak 12 orang $(20 \%)$.

Tabel 4

Masa Kerja Responden

\begin{tabular}{|l|l|l|}
\hline Masa Kerja & $\begin{array}{l}\text { Jumlah } \\
\text { responden }\end{array}$ & Persentase \\
\hline$<\mathbf{5}$ tahun & $\mathbf{1 2}$ & $\mathbf{2 0 . 0}$ \\
\hline 5-10 tahun & $\mathbf{1 8}$ & $\mathbf{3 0 . 0}$ \\
\hline$>10$ tahun & $\mathbf{3 0}$ & $\mathbf{5 0 . 0}$ \\
\hline Jumlah & $\mathbf{6 0}$ & $\mathbf{1 0 0 \%}$ \\
\hline
\end{tabular}

Dari 60 responden dalam penelitian ini terdapat responden kelompok masa kerja > 10 tahun sebanyak 30 orang (50\%), masa kerja 5-10 tahun sebanyak 18 orang (30\%), dan masa kerja $<5$ tahun sebanyak 12 orang $(20 \%)$.

Untuk melihat bahwa suatu data terdistribusi secara normal atau tidak. Model regresi yang baik adalah datanya terdistribusi secara normal atau mendekati normal (Bida, 2006). Dalam penelitian ini, digunakan diagram normal $\mathrm{P}$ plot untuk mengetahui distribusi data. Dari dua (2) grafik normal $\mathrm{P}$ plot cenderung menyebar disekitar garis diagonal dan mengikuti arah garis diagonal atau garis histogram. Hal ini berarti data yang digunakan dalam penelitian ini mengalami gejala normalitas.

Uji multikolinearitas dilakukan untuk mengetahui ada tidaknya korelasi yang sempurna. Indicator tidak terjadinya multikolinearitas adalah variance inflation factor /VIP disekitar angka 1, angka tolerance mendekati 1 , dan koeefisien korelasi antar variable independent harus lemah (dibawah 0,5). 
Hasil uji multikolinearitas menunjukkan bahwa nlai VIF dari kedua variabel sekitar angka 1, nilai tolerance mendekati 1, dan koefisien korelasi dibawah 0.5, maka dapat disimpulkan bahwa tidak terdapat masalah multikolnearitas pada model regresi ini.

Seperti yang telah dikemukakan sebelumnya, gejala heteroskedastisitas terjadi sebagia akibat dari variasi residual yang tidak sama untuk semua pengamatan, untuk mendeteksinya digunakan grafik Scatterplot. Dari hasil grafik dilihat titiktitik menyebar secara acak diatas dibawah angka nol pada sumbu Y. Hal ini menunjukkan bahwa tidak ada masalah heteroskidastisitas yang mengindikasikan varians konstan yang menghasilkan model estimator yang tidak bias. Maka dapat dikatakan model regresi memenuhi syarat untuk memprediksi implementasi kebijakan.

Hipotesis dalam pengujian ini adalah stres kerja, dukungan sosial, motivasi, beban kerja, dan terhadap kepuasan kerja anggota. Adapun hasil regresi dari data primer yang diolah dapat dilihat pada tabel berikut :

\section{Tabel 5}

\section{Hasil Uji Regresi Linier Berganda}

\begin{tabular}{|c|c|c|c|c|c|}
\hline \multirow{2}{*}{ Model } & \multicolumn{3}{|c|}{\begin{tabular}{|c|c|} 
Unstandardized & Standardized \\
Coefficients & Coefficients
\end{tabular}} & \multirow{2}{*}{$\mathrm{t}$} & \multirow{2}{*}{ Sig. } \\
\hline & B & $\begin{array}{c}\text { Std. } \\
\text { Error }\end{array}$ & Beta & & \\
\hline 1 (Constant) & 4.375 & 4.260 & & 1.027 & .309 \\
\hline $\begin{array}{l}\text { Sumber Daya } \\
\text { Manusia } \\
\text { (X1) }\end{array}$ & .986 & .132 & .702 & 7.497 & .000 \\
\hline $\begin{array}{l}\text { Struktur } \\
\text { Organisasi } \\
(\mathrm{X} 2)\end{array}$ & .142 & .184 & .072 & .771 & .444 \\
\hline
\end{tabular}

Persamaan regresi linear di atas dapat diketahui bahwa:

1. Nilai koefisien pada variabel sumber daya manusia (X1) adalah sebesar
0,986. Nilai tersebut berarti bahwa apabila terjadi kenaikan sumber daya manusia sebesar 1\%, maka implementasi kebijakan akan meningkat sebesar $0,986 \%$. Sebaliknya, apabila terjadi penurunan sumber daya manusia sebesar 1\%, maka implementasi kebijakan juga akan mengalami penurunan sebesar $0,986 \%$. Jadi, sumber daya manusia terhadap implementasi kebijakan mempunyai hubungan yang positif dengan pengembangan pariwisata pada Dinas Kebudayaan dan Pariwisata Kabupaten Banjar.

2. Nilai koefisien pada variabel struktur organisasi (X2) adalah sebesar 0,142. Nilai tersebut berarti bahwa apabila terjadi kenaikan struktur organisasi sebesar 1\%, maka implementasi kebijakan akan meningkat sebesar $0,142 \%$. Sebaliknya, apabila terjadi penurunan sumber daya manusia sebesar 1\%, maka implementasi kebijakan juga akan mengalami penurunan sebesar $0,142 \%$. Jadi, struktur organisasi terhadap implementasi kebijakan mempunyai hubungan yang positif dengan pengembangan pariwisata pada Dinas Kebudayaan dan Pariwisata Kabupaten Banjar.

Adapun hasil pengujian korelasi ganda (R) dapat dilihat pada tabel berikut:

Tabel 6 Hasil Uji Korelasi Ganda $\left(\mathbf{R}^{\mathbf{2}}\right)$

\begin{tabular}{|c|c|c|c|c|c|}
\hline Model & $\mathrm{R}$ & $\begin{array}{l}\text { R } \\
\text { Square }\end{array}$ & $\begin{array}{l}\text { Adjusted } \\
\text { R Square }\end{array}$ & $\begin{array}{l}\text { Std. } \\
\text { Error of } \\
\text { the } \\
\text { Estimate }\end{array}$ & $\begin{array}{l}\text { Durbin- } \\
\text { Watson }\end{array}$ \\
\hline 1 & $.718^{a}$ & .515 & .498 & 2.47422 & 1.839 \\
\hline
\end{tabular}


Berdasarkan tabel output SPSS model summary di atas, besarnya adjusted R2 adalah 0,498 atau sebesar 49,8\%. Hal tersebut berarti variasi implementasi kebijakan dapat dijelaskan oleh variasi dari kedua variabel independen, yaitu sumber daya manusia dan struktur organisasi sebesar 49,8\%. Sedangkan sisanya yang sebanyak $50,2 \%$ dijelaskan oleh sebabsebab lain di luar model dan/atau di luar variabel dalam penelitian ini.

$\begin{array}{ccc} & \text { Dari hasil pengujian uji } \mathrm{t} \text { di atas } \\ \text { yang } & \text { menggunakan } & \text { program }\end{array}$ SPSS 22, dapat disimpulkan bahwa:

1. Hipotesis Pertama

Berdasarkan hasil perhitungan diatas, diperoleh nilai t hitung adalah sebesar 7,497 dan nilai t tabel adalah sebesar 2,002 dengan nilai signifikannya sebesar 0,000, dimana nilai signifikannya lebih kecil dari 0,05. Oleh karena itu, hasil tersebut menunjukkan bahwa terdapat pengaruh yang positif dan signifikan antara sumber daya manusia dengan implimentasi kebijakan dalam pengembangan pariwisata di Dinas Kebudayaan dan Pariwisata Kabupaten Banjar. Hasil penelitian ini diperkuat oleh Dini Ariyani (2014) yang menyatakan bahwa sumber daya manusia berpengaruh signifikan terhadap output implementasi program pengembangan kawasan agropolitan Kabupaten Probolinggo. Penelitian Mening Subekti (2017) juga menyatakan bahwa sumber daya manusia berpengaruh signifikan terhadap terhadap efektifitas implementasi program bantuan operasional sekolah pada Satuan Pendidikan Sekolah Dasar Negeri Di Kecamatan Tambak.
2. Hipotesis Kedua

Berdasarkan hasil perhitungan diatas, diperoleh nilai t hitung adalah sebesar 0,771 dan nilai t tabel adalah sebesar 2,002 dengan nilai signifikannya sebesar 0,444, dimana nilai signifikannya lebih besar dari 0,05. Oleh karena itu, hasil tersebut menunjukkan bahwa tidak terdapat pengaruh yang signifikan antara struktur organisasi dengan implimentasi kebijakan dalam pengembangan pariwisata di Dinas Kebudayaan dan Pariwisata Kabupaten Banjar. Hasil penelitian ini sejalan dengan Mening Subekti (2017) bahwa struktur organisasi menunjukkan hasil yang tidak berpengaruh terhadap efektivitas implementasi BOS di kecamatan Tambak. Penelitian Raetina Tyas Putri (2012) juga menyatakan struktur organisasi tidak berpengaruh terhadap implementasi kebijakan pengendalian demam berdarah dengue di Kelurahan Sendangmulyo Kecamatan Tembalang Kota Semarang

3. Hipotesis Ketiga

Hasil dari uji statistik F ini dapat dilihat dalam tabel berikut ini:

Tabel 5.7

Uji F (simultan)

\begin{tabular}{|l|l|l|l|l|l|}
\hline Model & $\begin{array}{l}\text { Sum of } \\
\text { Squares }\end{array}$ & df & $\begin{array}{l}\text { Mean } \\
\text { Square }\end{array}$ & F & Sig. \\
\hline $1 \quad$ Regression & 370.992 & 2 & 185.496 & 30.301 & $.000^{\mathrm{b}}$ \\
Residual & 348.942 & 57 & 6.122 & & \\
Total & 719.933 & 59 & & & \\
\hline
\end{tabular}

Pada tabel ANOVA atau $\mathrm{F}$ test di atas didapat nilai $F$ sebesar 30,301 dengan nilai signifikansinya sebesar 0,000. Nilai signifikansi tersebut menunjukkan nilai yang jauh lebih kecil dari 0,05. Oleh karena itu, model regresi dapat digunakan untuk 
memprediksi implementasi kebijakan. Dengan kata lain bahwa vaiabel sumber daya manusia dan struktur organisasi secara bersama-sama berpengaruh terhadap dalam pengembangan pariwisata di Dinas Kebudayaan dan Pariwisata Kabupaten Banjar.

\section{Kesimpulan}

Berdasarkan pada data yang telah dikumpulkan dan pengujian yang telah dilakukan terhadap permasalahan dengan menggunakan persamaan model regresi berganda, maka dapat diambil kesimpulan

1. Terdapat pengaruh sumber daya manusia secara parsial terhadap implementasi kebijakanpengembangan pariwisata pada Dinas Kebudayaan dan Pariwisata Kabupaten Banjar.

2. Tidak terdapat pengaruh variabel struktur organisasi secara parsial terhadap implementasi kebijakan pengembangan pariwisata pada Dinas Kebudayaan dan Pariwisata Kabupaten Banjar.

3. Terdapat pengaruh variabel sumber daya manusia dan struktur organisasi secara simultan terhadap implementasi kebijakan pengembangan pariwisata pada Dinas Kebudayaan dan Pariwisata Kabupaten Banjar.

\section{Saran}

1. Struktur organisasi tidak berpengaruh dalam penelitian ini, disarankan bagi pimpinan instansi agar menjalin komunikasi lebih intens dan mensosialisasikan program-program kebijakan dalam pengembangan pariwisata.

2. Dinas Pariwisata dan Kebudayaan Kabupaten Banjar perlu mempromosikan dan memperkenalkan potensi daya tarik wisata kepada pasar wisatawan dengan bekerjasama berbagai pihak untuk membuat eventevent seni dan budaya yang diselenggarakan secara berkala dan terus menerus, tujuannya adalah agar masyarakat tetap melestarikan seni dan budaya.

3. Untuk mengetahui perkembangan pariwisata Kabupaten Banjar maka Dinas Pariwisata dan Kebudayaan pelu melakukan pertemuan rutin dari seluruh stakeholder sebagai wujud koordinasi, monitoring dan evaluasi bersama terhadap peta permasalahan pariwisata di Kabupaten Banjar, karena masalah bidang pariwisata dan kebudayaan Kabupaten Banjar tidak bisa hanya diselesaikan oleh satu pihak saja, melainkan seluruh stakeholder pariwisata yang ada.

4. Pengembangan pariwisata yang dilakukan pemerintah sebaiknya dimulai dengan perencanaan yang matang dan melalui kajian penelitian serta harus memperhatikan keberlanjutan ekologis, sosial budaya dan ekonomi masyarakat serta memberikan peluang lebih besar lagi bagi masyarakat lokal untuk ikut berpartisipasi dalam pengembangan pariwisata di tempat mereka, mulai dari proses perencanaan, pelaksanaan, pengawasan, maupun penerimaan manfaat dan keuntungan.

5. Dalam upaya memperkaya dan pengembangan ilmu pengetahuan, perlu dilakukan penelitian lanjutan untuk mengetahui variabel apa saja yang dapat mempengaruhi implementasi kebijakan pengembangan pariwisata pada Dinas Kebudayaan dan Pariwisata Kabupaten Banjar diluar 
faktor sumber daya dan struktur struktur organisasi.

\section{Daftar Pustaka}

Boove,L.Coutrland dan John V.Thill. 2004. Komunikasi Bisnis. Buku Pertama, Edisi Bahasa Indonesia. Edisi Keenam. PT Prenhalindo: Jakarta

Burack, E.H. dan Mathys N.J. 1993. Introduction to management: A Career Perspective. John Willey $\&$ Sons: New York

Anber dan Shireen. 2011. Service Quality Perspectives and Customer Satisfaction in Commercial Banks Working in Jordan. Middle Eastern Finance and Economics ISSN: 1450-2889 Issue 14

Cahyani, Ati, 2005. Strategi dan Kebijakan Manajemen Sumber Daya Manusia. PT Indeks Kelompok Gramedia : Jakarta

Cronbach, L.J., 1991. Methodological study-a personal retrospective, in Brennan, Robert, L., 2001, an essay on the history and future of reliability from the perspective of replications. Journal of Educational Measurement, 38.

Dewi, Sutrisna. 2007. Komunikasi Bisnis. Edisi I. Andi: Yogyakarta

Danim, Sudarwan. 2002. Menjadi Peneliti Kualitatif . Bandung: Pustaka Setia.

Darajat, Zakiah. 2010. Peranan Agama dalam Kesehatan Mental. Jakarta: CV Haji Msagung
Diab, Balqis. 2009. Analisis Pengaruh Nilai Pelanggan dan Citra Merek Terhadap Kepuasan Pelanggan Dalam Meningkatkan Retensi Pelanggan (Studi Kasus Pada Gies Batik Pekalongan). Tesis Program Studi Magister Manajemen Universitas Diponegoro.

Dunn, Willaim N. 2000. Pengantar Analisis Kebijakan Publik. Gadjah Mada University Press, Yogyakarta.

Edward III, G. C. 1980. Implementing Public Policy, New York: Congressional Querterly Press.

Ghozali, Imam. 2013. Aplikasi Analisis Multivariate Dengan Program IBM SPSS 19. Semarang: Badan Penerbit Universitas Diponegoro.

Hadi, S. 1991. "Analisis Butir Untuk Instrumen". Andi Offset: Yogyakarta

Kartasasmita,Ginanjar. 1996. Pembangunan Untuk Rakyat : Memadukan Pertumbuhan dan Pemerataan, Cetakan pertama, PT.Pusaka Cidesindo, Jakarta,

Notoatmodjo, S. 1998. Pengembangan Sumber Daya Manusia. Edisi Revisi. Cetakan Kedua. PT Rineka Cipta : Jakarta

Nugroho, Riant. 2003. Kebijakan Publik : Formulasi, Implementasi, Evaluasi. Jakarta : PT. Elex Media Panggabean, S. Mutiara. 2010. Manajemen Sumber Daya Manusia. Ghalia Indonesia; Jakarta 
Prayitno \& Amti, Erman. 2004. Dasardasar Bimbingan dan Konseling. Jakarta : Rieka Cipta.

Robbins, S dan Coulter, M. 2007, Manajemen. Edisi Kedelapan, Jakarta : PT Indeks.

Robbins, Stephen P. 2012. Organizational Behavior. Prentice Hall International, Inc. New Jersy

Siagian, P Sondang. 2008. Manajemen Sumber Daya Manusia. Cetakan kelima Belas. Bandung. Penerbit Bumi Aksara.

Simamora, H. 2006. Manajemen Sumber Daya Manusia. Edisi 3. Cetakan Kedua. Yogyakarta. STIE YKPN.

Sugiyono. 2010. Metode Penelitian Administrasi. Bandung: CV. Alfabeta

$\begin{array}{lll}\text { 2012. } & \text { Statistika } & \text { untuk } \\ \text { penelitian. } & \text { Bandung: } & \text { CV. } \\ \text { Alfabeta. } & & \end{array}$

Sulistiyani dan Rosidah. 2003. Manajemen Sumber Daya Manusia. Yogyakarta: Graha Ilmu.

Suryana. 2009. Statistika Terapan. www.statistikaterapan.wordpres.c om.

Susanto. A.B. et al. 2006. Strategi organisasi. Cetakan Pertama. Yogyakarta. Amara Books.

Suwanto dan Priansa, Donni Juni. 2011.
Manajemen SDM dalam
Organisasi Publik dan Bisnis.
Cetakan pertama. Bandung.
Penerbit Alfabeta.

Yamit, Zulian. 2010. Manajemen Kualitas Produk dan Jasa. Yogyakarta : Ekonosia.

Yusuf, Syamsu dan A. Juntika Nurihsan. 2008. Landasan Bimbingan dan Konseling. Bandung: Remaja Rosdakarya 